\title{
AVALIAÇÃO DO CENTRO DE ATENÇÃO PSICOSSOCIAL INFANTIL DE CASCAVEL - PR
}

\author{
Ana Silvia Scandolara, Angela Rockenbach, Emerson Aparecido Sgarbossa, \\ Lilian Rafaela Linke e Nelsi Salete Tonini \\ Universidade Paranaense, Cascavel, Brasil
}

\begin{abstract}
RESUMO: Estudo relacionado à avaliação de serviços em saúde mental, neste caso, o Centro de Atenção Psicossocial Infantil - CAPSi, do município de Cascavel-PR, serviço substitutivo implementado a partir da transformação da assistência psiquiátrica no Brasil. Objetivou avaliar qualitativamente o CAPSi. Os participantes foram 10 profissionais de saúde que atuam no CAPSi, sendo que os dados foram analisados sob a técnica do Discurso do Sujeito Coletivo (DSC) (Lefèvre \& Lefèvre, 2003). Como resultado, construíram-se 06 DSC e destacaram-se 12 temas geradores de significações: bom atendimento, estrutura física, recursos humanos, rede de serviços, acesso, referência, organização do serviço, família, atende as políticas de saúde mental, demanda, capacitação, redefinição de serviços, qualidade do serviço, papel do CAPSi e rotatividade de recursos humanos. Com base nos DSC o atendimento prestado no CAPSi é de boa qualidade, porém existem dificuldades de estrutura administrativa.
\end{abstract}

PALAVRAS-CHAVE: avaliação; reforma psiquiátrica; serviço de saúde mental.

\section{EVALUATION OF THE CHILD PSYCHOSOCIAL CARE CENTER OF CASCAVEL - PR}

\begin{abstract}
This study is related to the evaluation of mental health services, in this case, the Child Psychosocial Care Center - (Centro de Atenção Psicossocial Infantil - CAPSi), in the city of Cascavel-PR, that is a substitute service implemented from the transformation of the psychiatric assistance in Brazil. It objectified to evaluate CAPSi qualitatively. The participants have been 10 health professionals who act in CAPSi, and the data has been analyzed under the technique of the General Subject Speech ( Discurso do Sujeito Coletivo - DSC) (Lefèvre \& Lefèvre, 2003). As result, 06 DSC have been constructed and 12 meaning-generating themes have been distinguished: good attendance, physical structure, human resources, net of services, access, reference, organization of the service, family, respect for the mental health policies, demand, qualification, redefinition of services, quality of the service, role of the CAPSi and rotation of human resources. Based on the DSC, the attendance given at CAPSi is of good quality, however, difficulties of Administrative Structure exist.
\end{abstract}

KEYWORDS: evaluation; psychiatric reform; mental health service.

\section{Introdução}

Trata-se de um projeto de pesquisa relacionado com estudos de avaliação de serviços em saúde mental, neste caso, o Centro de Atenção Psicossocial Infantil - CAPSi, do município de Cascavel, implantado em 2004. O CAPSi é um serviço substitutivo implementado a partir da transformação da assistência psiquiátrica no Brasil, tem como finalidade atender crianças e adolescentes portadores de transtorno mental, constituindo-se na referência para uma população de cerca de 200.000 mil habitantes, ou outro parâmetro populacional a ser definido pelo gestor local, atendendo a critérios epidemiológicos.

São serviços de cuidado mais adequados aos princípios e diretrizes explicitados no Movimento da Reforma Psiquiátrica, iniciada com maior intensidade no Brasil a partir da década de 1980, que, em um pro- cesso de reformulação no sistema de saúde, questiona os saberes e práticas psiquiátricos e o espaço do hospital psiquiátrico como a única alternativa de tratamento para os indivíduos portadores de transtorno psíquico.

A Reforma Psiquiátrica não se restringe apenas à construção de uma nova rede de serviços, mas também à verdadeira cidadania dos sujeitos portadores de transtornos mentais. Por meio das políticas de saúde mental, a reforma visa à composição de serviços substitutivos à internação psiquiátrica tradicional, incluindo nesses serviços os CAPS, residências terapêuticas, atendimentos de urgência e emergência na atenção básica de saúde, além de leitos psiquiátricos em hospitais gerais (Tonini, 2005).

Os CAPSi são formalmente definidos pela Portaria $\mathrm{n}^{\circ} 224$ de 29 de janeiro de 1992 do Ministério da Saúde como unidades locais/regionalizadas, que oferecem atendimento de cuidados intermediários entre $\mathrm{o}$ 
regime ambulatorial e a internação hospitalar, em um ou dois turnos de quatro horas, por equipe multiprofissional, podendo atuar como porta de entrada da rede de serviços para as ações relativas à Saúde Mental. A portaria citada define também as características de cada modalidade em termos de capacidade operacional, funções, horários de funcionamento, atividades e recursos humanos (Brasil, 2004).

Assim buscou-se, com esta pesquisa, identificar como se dá o processo de trabalho dos técnicos que ali atuam, por meio do estudo do Centro de Atenção Psicossocial Infantil, o qual vai implicar acompanhar a construção de um serviço que se propõe a atender a inserção do usuário em seu contexto social e familiar com uma intervenção pautada na diversidade de saberes de uma equipe multiprofissional e na utilização de vários recursos.

O município de Cascavel encontra-se em fase de organização e implantação de uma rede de serviços em saúde mental. Mesmo existindo um Plano Municipal de Saúde Mental desde 2001, o mesmo só começou a ser efetivado a partir de 2003, sendo esse processo desencadeado após o fechamento do único Hospital Psiquiátrico do município credenciado pelo Sistema Único de Saúde (SUS), com 315 leitos. Esse hospital atendia toda a região que compõe a $10^{\mathrm{a}}$ Regional de Saúde, e tal fato levou Cascavel a acelerar o processo de implantação do Plano Municipal de Saúde Mental já aprovado pelo Conselho Municipal de Saúde.

Com a implantação e organização dos serviços de atenção à saúde ao indivíduo em sofrimento psíquico e seus familiares, as Unidades Básicas de Saúde (UBS) e Unidades de Saúde da Família (USF) tornam-se, a partir de novembro de 2003, porta de entrada para os serviços especializados em Psiquiatria e Saúde Mental, substituindo o hospital psiquiátrico que anteriormente era a porta de entrada para os portadores de transtornos psiquiátricos.

A expansão dessa forma de atendimento em diversos municípios do país indica que, como política pública de atenção em saúde mental, os CAPS têm sido percebidos como tendo potencial para responder, de forma efetiva, às questões locais, configurando-se como um dos equipamentos centrais da implantação do Sistema Local de Saúde Mental. Por outro lado, as diversidades contextuais não permitem que esse processo ocorra de forma linear e homogênea. Fatores técnicos, políticos, econômicos, culturais, entre outros, têm condicionado a implementação dessas práticas.

Partindo das considerações apontadas anteriormente, o objetivo desta pesquisa foi identificar, na visão dos diferentes profissionais que atuam no CAPSi do município de Cascavel- PR, as dificuldades existentes em sua área de atuação, bem como as ações que visem propostas de melhoria do serviço.

\section{Material e método}

Buscando conhecer a dinâmica do processo de trabalho dos profissionais que atuam no CAPSi, verificando as relações, contradições e subjetividade dos envolvidos e com intuito de atingir os objetivos propostos para este estudo, propôs-se a realização de uma pesquisa qualitativa, a partir do referencial da pesquisa social.

O trabalho de campo foi realizado durante o período de julho de 2007, no Centro de Atenção Psicossocial Infantil do município de Cascavel, localizado na Região Oeste do Estado, sob a coordenação da Secretaria Municipal da Saúde.

De acordo com a Secretaria de Saúde do Município de Cascavel, o objetivo do CAPSi é o de garantir a assistência à criança e ao adolescente com transtorno mental e de comportamento, dando suporte ao usuário e sua família, visando sua recuperação e a reinserção na comunidade.

Os sujeitos que participaram da presente pesquisa foram 10 profissionais de saúde que atuam no CAPSi (médicos, enfermeiros, assistentes sociais, terapeuta ocupacional, psicólogo, educador físico), por serem os sujeitos responsáveis pela execução das ações voltadas aos adolescentes e crianças portadores de transtorno psíquico atendidos nesse serviço.

Para coleta de dados, foi utilizada a entrevista aberta, gravada e transcrita na íntegra, a qual não ultrapassou 30 minutos, realizada com $10(\mathrm{dez})$ profissionais que atuam no serviço, com hora marcada previamente com cada participante. O contato foi feito no próprio serviço por meio das reuniões, e as questões norteadoras totalizaram três, que abordaram o atendimento no CAP$\mathrm{Si}$, quais sejam: 1) Como você percebe o atendimento oferecido neste serviço? 2) Me fale sobre os problemas que identifica no funcionamento do serviço? 3) Me fale como poderia melhorar o serviço? As entrevistas foram realizadas após aprovação do comitê de ética em Pesquisa Envolvendo Seres Humanos (CEPEH), da Universidade Paranaense (UNIPAR), conforme certificado aprovado sob o protocolo $\mathrm{n}^{\circ}$. 10078/2007.

Para organização e análise dos dados obtidos nas entrevistas, utilizou-se como técnica o Discurso do Sujeito Coletivo (DSC), pois esse busca dar conta da discursividade, característica própria e indissociável do pensamento coletivo, buscando preservá-la em todos os momentos da pesquisa, desde a elaboração das perguntas, passando pela coleta e pelo processamento dos dados, até culminar com a apresentação dos resultados, e também foram extraídos os temas geradores de significação de cada questão (Lefèvre \& Lefèvre, 2003).

Para confeccionar os Discursos do Sujeito Coletivo (DSC), foram utilizadas as seguintes figuras metodológicas (Lefèvre \& Lefèvre, 2003): 
- Expressões-chave (ECH) - São pedaços, trechos ou transcrições literais do discurso que revelam a essência do depoimento, são a matéria-prima para a construção dos Discursos do Sujeito Coletivo, portanto devem ser sublinhadas, coloridas pelo pesquisador. Um dos cuidados a ser tomado quanto à seleção das $\mathrm{ECH}$, é desprezar tudo que é irrelevante, acessório, buscando extrair o máximo possível, com a essência do pensamento tal como ela aparece, literalmente, no discurso analisado (Lefèvre \& Lefèvre, 2003).

- Ideias centrais (IC) - é um nome ou expressão linguística que revela e descreve de maneira fidedigna o sentido de cada um dos discursos analisados e de cada conjunto homogêneo de ECH, que vão dar origem ao DSC.

É importante destacar que a IC não é uma interpretação, mas uma descrição do sentido de um depoimento ou de um conjunto de depoimentos.

- Discurso do Sujeito Coletivo (DSC) - é um discurso-síntese redigido na primeira pessoa do singular e composto pelas Expressões-Chave que têm a mesma Ideia Central. A proposta do DSC como forma de conhecimento ou redução da variabilidade discursiva empírica implica um radical rompimento com a lógica quantitativo-classificatória, na medida em que se busca resgatar o discurso como signo de conhecimento dos próprios discursos.

Uma pesquisa pode produzir mais que um DSC, e esses podem se caracterizar por sua complementaridade ou por diferença. Os autores da proposta recomendam que, no caso de serem DSC caracterizados por diferença, esses devem ser apresentados separadamente, enquanto que se for por complementaridade, fica a critério do pesquisador preferir apresentar resultados mais detalhados ou mais genéricos.

Ao finalizar a construção do DSC, a sistematização é apresentada como se o discurso de todos fosse o discurso de um e, para isso, deve-se selecionar fragmentos da fala, limpando-as das particularidades e, ainda, dos trechos repetidos ou muito semelhantes, escolhendo-se apenas um para compor o DSC.

\section{Resultados e discussão}

Nesta etapa, são apresentados os dados referentes aos discursos dos dez profissionais de saúde que atuam no CAPSi. Os DSC foram construídos com fragmentos de falas individuais, semelhantes a um quebra-cabeça, como forma de expressar uma determinada ideia, ou seja, um dado pensamento ou representação social sobre as questões elencadas por esta pesquisa. Construíramse seis DSC e destacaram-se dez temas geradores de significação, quais sejam: bom atendimento; reinserção social; deficiência de recursos humanos; rede de serviços (organização do serviço); acesso (demanda); referência; participação familiar; atende as políticas de saúde mental; capacitação profissional e qualidade dos serviços, os quais serão discutidos e referendados a seguir.

Em relação à primeira questão, quando perguntado "Como você percebe o atendimento oferecido neste serviço?", apresentam-se abaixo os dois DSC e os três temas geradores de significação (bom atendimento; reinserção social; deficiência de recursos humanos) surgidos nos discursos dos sujeitos.

\section{Primeiro DSC:}

Todos os procedimentos e atendimentos são de boa qualidade, são completos, público credenciado pelo Sistema Único de Saúde, ajuda bastante as crianças e adolescentes com transtorno mental que frequentam o CAPSi. Apesar de poucos funcionários a equipe faz um trabalho consciente de atendimento multiprofissional englobando assistência psiquiátrica, psicológica, orientações com professores e monitores das oficinas terapêuticas, trabalho bem completo para a reinserção social dessas crianças e adolescentes, a equipe faz de tudo para melhorar, cada um dando o que tem de si para ajudar. É importante tanto para a sociedade como para nós profissionais.

\section{PRIMEIRO TEMA: Bom Atendimento}

Atendimento corresponde ao ato de cuidar, de prestar atenção às pessoas que recebemos ou com as quais mantemos contato. Requer de quem pratica muita responsabilidade e um estado de espírito baseado na competência (Tonini, 2005).

É uma ação de comunicar-se, transmitir algo em uma linguagem compreensível ao outro. A comunicação é tudo o que um profissional de atendimento usa para exercer o seu trabalho, que vai da sua capacidade de comunicar-se até a mensagem que ele transmite.

A comunicação é o elo entre a Instituição e o seu público. Portanto, o profissional de saúde é o agente dessa comunicação. Nesse sentido, a comunicação é qualquer processo pelo qual um pensamento é transmitido de pessoa para pessoa, sem perder, tanto quanto possível, a sua intenção ou conteúdo original.

Relacionado com o bom atendimento, temos também o relacionamento humano, que nada mais é do que a maior ou menor capacidade do ser humano de conviver ou comunicar-se com seus semelhantes. Assim, o relacionamento profissional é uma ligação de amizade profissional condicionada a uma série de atitudes recíprocas, e nós, como profissionais de saúde, devemos ter e manter um comportamento adequado, que leve a pessoa a um retorno favorável. 
SEGUNDO TEMA: Reinserção Social

O modelo tradicional de assistência à saúde mental, baseado na exclusão do sujeito do convívio social, apresentava sinais de esgotamento desde o final da década de 70, mais precisamente depois da Segunda Guerra Mundial. Em tempos de crescimento econômico e reconstrução social, de grande desenvolvimento dos movimentos civis, de maior tolerância e sensibilidade para com as diferenças e minorias, a comunidade profissional e cultural, por vias diferentes, chega à conclusão de que os hospitais psiquiátricos deveriam ser transformados ou abolidos (Desviat, 1999).

A luta pela reforma psiquiátrica e pelo processo de desinstitucionalização em construção no Brasil busca construir espaços de debate, solidariedade, afetividade, ou seja, espaços de atenção psicossocial. Tal luta exige de todos os profissionais, familiares e sociedade como um todo rever conceitos, métodos e formas de lidar com o sofrimento psíquico. Busca principalmente humanizar também o cuidado em saúde mental, porém vai além, pois está pautada na premissa de possibilitar ao excluído, o portador de transtorno mental, o seu direito de cidadão como ser humano sujeito da história, componente da sociedade e responsável por essa também (Tonini \& Kantorski, 2005).

Nos Discursos do Sujeito Coletivo, percebemos que existe consenso em relação à busca de uma sociedade mais justa para esses indivíduos, quando apontam a Reinserção Social como positividade no cotidiano de CAPSi. Esse objetivo comum estimula os profissionais a discutir estratégias não-excludentes para atender os familiares e indivíduos em sofrimento psíquico.

Estabelecer um novo olhar dos profissionais a partir de uma mudança estrutural pode significar um avanço no cuidado em saúde mental. Um cuidado que necessita de espaços terapêuticos diversificados, entre eles, grupo de familiares, grupo de medicação, oficinas terapêuticas de criação, expressão e produção, atendimento individual, visita domiciliar, assembleia de usuários, familiares e equipe, busca de faltosos, reunião de equipe, atividades de integração com a comunidade.

\section{Segundo DSC}

A demanda de pacientes que são encaminhados pelas unidades básicas de saúde é grande gerando lista de espera, tanto para avaliação com a psicóloga quanto para psiquiatra, são os procedimentos oficiais e depois também para as oficinas terapêuticas. Poderíamos atender toda população, no entanto a gente consegue atender apenas uma parcela, porque a demanda é muito grande e a gente tem poucas vagas para oferecer e deficiência de recursos humanos. O serviço necessita de um psiquiatra permanente que ficasse a semana toda, oito horas diárias, deveria também ter um espaço físico melhor, oficinas maiores e grupos menores, porém a gente consegue atende apesar dessas dificuldades.

TERCEIRO TEMA: Deficiência de Recursos Humanos

Segundo Tonini (2005), é necessário que os profissionais que atuam nos serviços de saúde mental tenham uma nova forma de compreender e abordar a loucura, buscando instaurar uma nova resposta social ao adoecimento e ao portador de sofrimento psíquico. Para tanto, de acordo com Furtado e Campos (2005), é importante que esses profissionais tenham uma postura distinta do modelo anterior, de modo a não apenas serem criadas novas técnicas de tratamento, mas que este trabalho tenha como princípio norteador, uma ética inclusiva.

Furtado e Campos (2005, p. 109) acrescentam que:

a formação de profissionais no próprio serviço é uma alternativa, no entanto ... a formação permanente ainda que imprescindível é insuficiente na geração de novas posturas éticas, de um novo posicionamento e abertura diante daquele que padece de sofrimento psíquico.

Com relação à questão dois, "Me fale sobre os problemas que identifica no serviço", apresentam-se abaixo os dois DSC e os quatro temas geradores de significação - rede de serviços (organização do serviço), acesso (demanda/referência), participação familiar e atende as políticas de saúde mental - surgidos nos discursos dos sujeitos.

\section{Primeiro DSC}

O principal deles, é a falta de serviços de saúde mental na rede municipal de saúde, como por exemplo, a burocracia, a dificuldade financeira e a falta de um ambulatório infantil, um serviço de referência para os usuários que recebem alta do CAPSi. Com relação a demanda, há lista de espera e a gente não tem onde encaminhar, as vezes temos que atender uma demanda que não é nossa, aqui atendemos crianças e adolescentes de zero a vinte e um anos que tem transtornos mentais, mas alguns transtornos, que são subjacentes, a gente não atende aqui, porém não tem para onde encaminhar, $e$ acabamos recebendo e não oferecendo um atendimento de qualidade, como exemplo problemas de déficit de aprendizagem que, neste caso, deveria haver um convênio com a secretaria de educação. Ainda no que se refere à procura pelo serviço, talvez fosse necessária a implantação de um outro CAPS. Outro problema é a não participação de $100 \%$ dos usuários nas oficinas terapêuticas, bem como a pouca participação da família, que às vezes tem bastante resistência em participar O espaço físico em que atendemos os 160 pacientes é inadequado, muito pequeno. Temos alguns problemas com a equipe, por exemplo o médico psiquiátrico que não tem na rede, deveria estar aqui todos os dias, po- 
rém não é nossa realidade, existe uma dificuldade na contratação desses profissionais, sendo que há apenas dois para atender todo o municipio, este profissional poderia estar fazendo também um acompanhamento com o resto da equipe técnica, para dar mais qualidade ao trabalho. Nas oficinas, que agora tem um professor adequado, devido término dos contratos, haverá um desfalque muito grande de profissionais. Deveriam haver cursos de capacitação, orientando-nos a lidar com as deficiências. Há também a questão do acesso ao CAPSi, já que as crianças, geralmente, têm poucas condições sociais e não estão recebendo o passe livre.

PRIMEIRO TEMA: Rede de serviços (organização dos serviços)

O processo de reestruturação do setor da saúde coloca como desafio a implementação de mudanças que permitam enfrentar, de forma urgente e eficaz, a situação de saúde atualmente observada no país, sem perder de vista o fato de que tal situação é resultado das condições gerais de vida da população, o que limita e subordina as ações setoriais ao contexto mais amplo (Fekete, 1997).

Essa rede, composta por modalidades diversificadas de atenção e integrada à rede básica territorializada, deve contemplar ações referentes às áreas de trabalho, moradia e educação e, também, ser estruturada de forma descentralizada, integrada e intersetorial, de acordo com as necessidades dos usuários, visando garantir o acesso universal a serviços públicos humanizados e de qualidade.

Para consolidação dessa rede de atenção em saúde mental, a Secretaria Estadual de Saúde do Paraná estabelece metas a partir das diretrizes do Ministério da Saúde, definindo em seu planejamento estadual alguns programas na área de saúde mental, os quais vêm dando balizamento para os municípios do Estado do Paraná. São eles:

1. Programa de expansão e fortalecimento da rede de serviços extra-hospitalares: Centros de Atenção Psicossocial - (CAPS I, II, III; CAPSi; CAPSad); serviços residenciais terapêuticos; leitos psiquiátricos em hospital geral; ambulatórios de saúde mental; 2 . Inclusão das ações de Saúde Mental na atenção básica (Programa Saúde da Família e nas Unidades Básicas de Saúde); 3. Programa de formação e qualificação de recursos humanos dos municípios para ações de Saúde Mental (Núcleos de capacitação para a Reforma Psiquiátrica/cursos de especialização, cursos de atualização, cursos de informações técnicas); 4. Reestruturação dos serviços próprios; 5 . Programa de Atenção Comunitária a usuários de Álcool e Outras Drogas; 6. Programa de Avaliação dos hospitais psiquiátricos - PNASH/Psiquiatria; 7. Implantar as Comissões Revisoras de Internações
Psiquiátricas (Comitê Estadual; Comissões Regionais); 8. Implantação do Programa Nacional "De Volta Para Casa" (Paraná, 2005).

Segundo Tonini e Kantorski (2005), se em nível de elaboração teórica pode-se considerar que ocorreram avanços nas propostas de reorganização setorial, nos aspectos operacionais os resultados são menos expressivos. No discurso dos sujeitos participantes desta pesquisa, encontram-se demonstradas as dificuldades em se traçar ações/operações na área de saúde mental.

Devemos lembrar que a reorganização da assistência à saúde no Brasil é muito recente e que ela envolve fatores econômicos, culturais e políticos. Os setores da sociedade mais favorecidos economicamente, por exemplo, abandonam o sistema público e buscam alternativas, como os seguros de saúde privados. Isso acontece junto com a universalização da assistência. Ocorre, ainda, um racionamento na oferta dos serviços (poucos médicos, serviços em número insuficiente, entre outros), especialmente nos municípios de pequeno porte. Assim, em vez de incluir toda a população (universalização), o sistema público de saúde brasileiro, ao oferecer um serviço de má qualidade, exclui aqueles que têm condições financeiras de comprar serviços de melhor qualidade e acaba servindo somente os setores mais carentes da sociedade.

A partir do processo de Reforma Psiquiátrica iniciado no país, a assistência prestada ao portador de transtorno mental torna-se elemento de um conjunto maior de ações que englobam diferentes setores (o serviço, o governo, o movimento social, a sociedade) e que compõem esses vários sentidos em um só (político, cultural, jurídico, trabalhista). Desse modo, a discussão sobre a loucura não se restringe somente ao campo técnico, ampliando-se para o campo da cultura e da ética (Tonini \& Kantorski, 2005).

SEGUNDO TEMA: Acesso (Demanda / Referência)

Com a municipalização e a expansão das ações de saúde mental, os objetivos que envolvem a melhoria da qualidade de atendimento podem ser concretizados e há maiores possibilidades de que a população seja mais bem assistida. Está citado no documento "Normas de Atendimento em Saúde Mental" (Paraná, 2003), complementar à Portaria $n^{\circ}$ 224/92/MS, que para a implantação de qualquer um dos serviços é imprescindível a existência, no município ou consórcio de municípios, de uma rede hierarquizada de cuidados em saúde mental, isto é, a implantação de um serviço de determinada complexidade pressupõe a existência dos serviços de menor complexidade, serviços esses previstos no Plano Municipal de Saúde, devidamente aprovado pelo Conselho Municipal de Saúde. 
Portanto, para que o sistema de referência e contrarreferência funcione adequadamente, é necessário que os diversos serviços, especializados ou não, estejam articulados.

É importante considerarmos o perfil heterogêneo dos municípios na hora de pensar essa articulação com os diversos serviços especializados, de modo a enfrentar suas dificuldades na implantação da reforma psiquiátrica. A dificuldade de contratação de pessoal especializado e a falta de conhecimento específico dos profissionais que atuam na atenção básica dificultam o acesso da população ao tratamento, bem como a implantação de ações de saúde mental na atenção primária. Estas devem obedecer ao modelo de redes de cuidado, com base territorial e atuação transversal com outras políticas específicas, com objetivo de estabelecimento de vínculos e de acolhimento dos indivíduos com sofrimento psíquico e seus familiares.

Considerando a inquietação dos profissionais explicitada por meio de suas falas sobre a necessidade de um local para encaminhar os pacientes no momento da crise, devemos lembrar que a estratégia para garantir o acesso precisa ser estabelecida desde a rede básica. As unidades de saúde, segundo Campos (2003), devem ser reorganizadas em Equipes Locais de Referência (Equipes de Saúde da Família), responsáveis pelo atendimento integral às famílias e seus pacientes com transtorno mental, e equipes de apoio, Equipe Matricial, encarregadas de cooperar com a ESF em áreas específicas, como saúde mental e reabilitação, por exemplo.

\section{TERCEIRO TEMA: Participação da Família}

Seguindo Pereira e Bellizzoti (2004), à medida que os serviços ampliam sua extensão e visualizam a importância do projeto terapêutico, a família aparece como protagonista das estratégias de cuidados, tornando-se parte do processo reabilitativo que visa a promoção da pessoa, aumenta as habilidades e impulsiona a criação de um sistema continuado de apoio social.

A relação da família com o indivíduo com transtorno mental aparece não só como um problema social a ser equacionado pela sociedade, mas também como uma questão teórica, que deve ser trabalhada e justificada cientificamente para buscarmos a proximidade entre a família e o seu doente, pois a mesma ficou muito tempo aguardando pacientemente a devolução de seu familiar recuperado ou curado, no modelo assistencial asilar. Esse centrava sua atenção no indivíduo com transtorno mental, excluindo a família de sua abordagem, a qual tinha o papel restrito de identificar a loucura, encaminhar o seu portador ao asilo para cuidados médicos, visitá-lo esporadicamente e fornecer informações necessárias sobre a história de sua enfermidade (Rosa, 2003).
Segundo Cianciarullo (2002), a família tem como pressupostos básicos o desenvolvimento emocional, a socialização, a organização dos papéis das relações e de seus membros com a comunidade e a preservação do patrimônio. Atualmente, ela constitui-se provavelmente num dos mais importantes contextos no qual as ações de saúde materializam-se, buscando equacionar o processo saúde/doença.

Acreditamos que, para mudar esse quadro em que a família é vista como um problema, os profissionais de saúde devem entender a importância da participação do familiar desde o momento da definição da necessidade de buscar ajuda, onde e com quem, passando pelo suporte das condutas indicadas, até a finalização do processo de intervenção e incorporação, validação ou não das ações indicadas para a manutenção ou melhoria das condições crônicas ou agudas dos usuários dos serviços de saúde (Cianciarullo, 2002).

Conforme Melman (2001), com o processo da Reforma Psiquiátrica, um número cada vez maior de pessoas passam a ser assistidas em serviços extrahospitalares, introduzindo novos elementos no campo de negociação entre famílias e o campo da saúde mental, abrindo caminhos para as partes rediscutirem as bases de uma nova relação. Nesse cenário, as famílias se viram estimuladas e pressionadas a voltar a assumir a responsabilidade pelo cuidado de seus membros adoecidos.

\section{Segundo DSC}

A gente sempre está tentando melhorar, dentro do possivel, dentre tantas oficinas que dispõe, o CAPS é, dentro de um parâmetro nacional, um dos melhores, temos cinco a oito oficinas por periodo, para todos os tipos de transtornos, então é bom o lugar.

QUARTO TEMA: Atende as políticas de saúde mental No ano de 1992 foram estabelecidos "padrões mínimos para o funcionamento dos serviços de saúde mental" (Amarante, 1994, p. 2001). Esses padrões mínimos parecem estar sendo respeitados quando se tem que um dos DSC foi que "dentre tantas oficinas que dispõe, o CAPS é, dentro de um parâmetro nacional, um dos melhores, temos cinco a oito oficinas por período, para todos os tipos de transtornos, então é bom o lugar".

Para encerrar a entrevista, perguntamos "Me fale como poderia melhorar o serviço". Construíram-se dois DSC, destacando-se três temas geradores de significações, sendo eles: organização dos serviços (redefinição de serviços, demanda), capacitação profissional e qualidade do serviço.

\section{Primeiro Discurso Sujeito Coletivo}

Tem bastante coisa a melhorar, como criar ambulatório para atendimento infantil, porque aqui ele é extra hospitalar. Redefinir demanda de outros serviços que 
tem uma demanda parecida com o nosso, tendo também um terceiro turno, só para avaliação, psicoterapia e consulta psiquiátrica. Teria que aumentar a equipe e espaço físico, talvez, a abertura de mais um CAPS na região leste para favorecer outra população e dar maiores condições de acessibilidade aos pacientes. Outro fator seria a criação de mais vagas, horas de procedimento e atendimento de psiquiatria e psicologia e esclarecimento à população, bem como, cursos de capacitação para entendermos o problema de cada criança atendida ou, seria melhor se os profissionais já viessem qualificados. Melhorar a rede em saúde mental aumentando a comunicação entre saúde, educação e justiça, que hoje é uma questão séria do CAPS, em que as crianças que tem déficit de aprendizagem, que é pedagógico, vêm parar aqui no CAPS, que seria um tratamento em relação ao comportamento das crianças com o transtorno, ter um retardo mental só por ele, não tem porque vir tratar aqui, ter uma dislexia, não é aqui o local de ser tratado, assim, o déficit de aprendizagem não vem. Acho que aumentando a comunicação intersetorial, talvez melhore muito o entendimento do que é um CAPS, do que é um trabalho com transtorno mental infantil no município, até porque às vezes vem muitas determinações do juiz, que quer esclarecimentos, os quais não lhe cabe saber, como o que a criança tem e porque que precisa de tal medicamento. Penso que poderia ter um horário mais dinâmico, em que a criança não ficasse o tempo todo aqui, e sim os pais, pois em $80 \%$ dos casos, o problema é com eles, que não sabem tratar e comandar os filhos. Assim, as oficinas, que são oito, que sejam quatro repartidas entre pais e parentes próximos. Precisaríamos mais autonomia e recursos financeiros, afinal, dependemos quase 100\% do que vem da prefeitura. Que não tivesse esse contrata e pára contrato, tendo que os profissionais com experiência sair para entrada de um pessoal novo. Para os adolescentes, algo profissionalizante, que os permita conseguir um emprego ao sair daqui.

PRIMEIRO TEMA: Organização dos serviços (redefinição de serviços/ demanda)

A reorganização do modelo assistencial em saúde mental preconizada no contexto da reforma psiquiátrica necessita ser pautada em uma concepção de saúde compreendida como processo, e não como ausência de doença, na perspectiva de produção de qualidade de vida, enfatizando ações integrais e promocionais de saúde.

A efetivação da Reforma Psiquiátrica requer agilidade no processo de superação dos hospitais psiquiátricos e a concomitante criação da rede substitutiva que garanta o cuidado, a inclusão social e a emancipação das pessoas portadoras de sofrimento psíquico. Nessa perspectiva, é necessário que os municípios desenvolvam políticas de saúde mental mediante a implementação de uma rede de serviços substitutivos ao hospital psiquiátrico, territorializados e integrados à rede de saúde que realize ações de proteção, promoção, prevenção, assistência e recuperação em saúde mental (Brasil, 2002).

SEGUNDO TEMA: Capacitação profissional

Para Furtado e Campos (2005), avançar no processo da Reforma Psiquiátrica significa ir além da simples implementação de novos serviços e, para isso, necessitamos ter um quadro de profissionais imbuídos de uma postura profissional profundamente distinta do modelo anterior, sobretudo se considerarmos que as novas modalidades de atenção em saúde mental não se resumem a novas técnicas de tratamento, mas constituem-se numa ética de inclusão.

Conforme Tonini e Kantorski (2005), o avanço do processo da Reforma Psiquiátrica no Brasil requer a ampliação das instâncias de capacitação dos diferentes agentes do cuidado no campo da saúde mental, para além das universidades, e exige, nas três esferas do governo, que os centros de Formação de Recursos Humanos estabeleçam as bases para criar imediatamente programas estratégicos interdisciplinares e permanentes de formação de Recursos Humanos em saúde mental para o SUS.

Essa política de formação e capacitação deve criar espaços de troca baseados na realidade local, com valorização dos diversos saberes e metodologia participativa, construída por meio de intercâmbio entre os municípios, coordenadorias regionais e Estados, e entre serviços e instituições formadoras, voltadas para profissionais de saúde em todos os níveis de atenção, considerando a competência técnica e política desejada. Nesse processo, torna-se fundamental incluir usuários e familiares voluntários nas oficinas de capacitação em saúde mental, como parte da equipe de instrutores (Brasil, 2002).

Acreditamos que essa necessidade de capacitação de Recursos Humanos em Saúde Mental seja uma realidade nacional. Atualmente, esta responsabilidade está a cargo do "Polo de Capacitação, Formação e Educação Permanente em Recursos Humanos para o Sistema Único de Saúde". Este é formado por representantes de instituições de Saúde Estaduais e Municipais e de instituições de ensino superior, públicas e privadas, que têm como atribuição assessorar e aprovar projetos de capacitação de recursos humanos para os diferentes serviços de saúde da rede pública.

Porém, existe uma preocupação com as instituições de formação as quais ainda assimilam poucas discussões trazidas pela Reforma Psiquiátrica e vêm oferecendo tímidas contribuições em termos de avaliação e propostas para o seu desenvolvimento (Tonini \& Kantorski, 2005).

Segundo Discurso Sujeito Coletivo

Apesar dos problemas, conseguimos trabalhar bem com o que temos, desta forma o andamento do CAPS 
está indo bem, melhor que no início, quando haviam menos funcionários. Eu acho que o serviço oferecido pelo CAPS, é um dos melhores que já vi, e que posso estar participando em relação ao tratamento do transtorno mental infantil. Tem uma equipe muito boa, procuramos fazer o melhor e acreditamos que é bom trabalho, de qualidade excepcional.

TERCEIRO TEMA: Qualidade do serviço

Nogueira (1994) salienta que o atendimento das necessidades e das expectativas dos usuários dos serviços de saúde, de maneira eficiente e eficaz, é a questão norteadora dos pressupostos filosóficos e das bases metodológicas que vêm orientando as ações das organizações. Assim, o sistema de saúde brasileiro vem enfrentando, nas últimas décadas, um novo imperativo: a busca pela gestão da qualidade dos serviços.

A gestão da qualidade refere-se ao processo ativo de determinar e orientar o caminho a ser seguido para atingirmos os objetivos empregando todos os recursos contidos na produção de um bem ou de um serviço.

\section{Conclusão}

Levando em consideração o princípio de que a avaliação da eficácia de um serviço é a verificação da consecução dos fins propostos para resolver um problema, necessitamos estabelecer critérios iniciais a partir dos quais avaliamos se o CAPSi está conseguindo alcançar os fins a que se propõe. Partimos, então, das recomendações do Relatório Final da $2^{a}$ Conferência Nacional de Saúde Mental e do próprio objetivo proposto pelo CAPSi.

Conforme esses documentos, a atenção integral e a luta pela cidadania das pessoas com transtornos mentais são os marcos conceituais que devem sustentar o modelo de atenção à saúde mental.

Com base nos DSC, o atendimento prestado no CAPSi é de boa qualidade e busca a reinserção desses jovens na sociedade. Existem dificuldades apontadas que merecem destaque: organização dos serviços (redefinição de serviços, demanda); capacitação profissional; participação da família; deficiência de recursos humanos.

A proposta da reforma psiquiátrica de envolvimento da família e comunidade nos serviços de atenção em saúde mental visa promover a reabilitação psicossocial do indivíduo, em que esta é entendida como um processo de reconstrução, de busca pelo exercício pleno da cidadania e também pela contratualidade nos três cenários: habitat, rede social e trabalho com valor social (Pitta, 1996).

Constatamos ainda com esta pesquisa que a construção de rede alternativa de serviços de saúde mental no município de Cascavel, particularmente o CAPSi, está indo no caminho certo. Porém, fica claro que existem dificuldades que precisam ser superadas pelos profissionais, gestores e sociedade. Pois, para resgatar a cidadania dos usuários, não basta que eles participem em número dos serviços de saúde mental, pois cidadania não é fenômeno quantitativo, e sim qualitativo, e "na qualidade não vale o maior, mas sim o melhor; não o extenso, mas o intenso; não o violento, mas o envolvente; não a pressão, mas a impregnação" (Demo, 1999, p.18).

\section{Referências bibliográficas}

Amarante, P. (1994, dezembro). Algumas reflexões sobre a ética, cidadania e desinstitucionalização na reforma Psiquiátrica. Saúde em Debate, 45, 43-46.

Brasil. Ministério da Saúde. Sistema Único de Saúde. Conselho Nacional de Saúde. (2002, 11 a 15 de dezembro). Relatório Final da III Conferência Nacional de Saúde Mental. Brasília, DF: Autor.

BRASIL. Ministério da Saúde. Coordenação Geral de Saúde Mental. (2004). Saúde Mental no SUS. Informativo da Saúde Mental. Brasília, DF: Autor.

Campos, G. W. (2003). Saúde Paidéia. São Paulo: HUCITEC.

Cascavel. Secretaria de Saúde do Município. (2004). Unidades Especiais de Saúde. Acesso em 19 de novembro, 2008, em http://www.cascavel.pr.gov.br/saude/unidades especiais

Cianciarullo, T. I. (2002). (Org.). Saúde na família e na comunidade. São Paulo: ROBE.

Demo, P. (1999). Avaliação qualitativa. Polêmicas do nosso tempo. Campinas, SP: Autores Associados.

Desviat, M. (1999). A reforma psiquiátrica. Rio de Janeiro: Fiocruz.

Fekete, M. S. (1997). Estudo da acessibilidade na avaliação dos serviços de saúde. In J. P. de Santana (Org.), Desenvolvimento gerencial de unidades básicas do Sistema Único de Saúde (SUS) (pp. 114-120). Brasília, DF: Organização Pan Americana da Saúde.

Furtado, J. P. \& Campos, R. O. (2005, março). A transformação das políticas de saúde mental no Brasil para a prática nos novos serviços. Rev. Latinoam. Psicopat. Fund., 8(1), 109-122.

Lefèvre, F. \& Lefèvre, A. M. C. (2003). O discurso do sujeito coletivo: um novo enfoque em pesquisa qualitativa. Caxias do Sul, RS: EDUCS.

Melman, J. (2001). Família e doença mental: repensando a relação entre profissionais de saúde e familiares. São Paulo: Escrituras Editora.

Nogueira, P. N. (1994). Perspectivas da qualidade em saúde. Rio de Janeiro: Qualitymark.

Paraná. Secretaria Estadual de Saúde. (2003). Plano Diretor de Regionalização. Acesso em 07 de julho, 2008, em http://www. saude.pr.gov.br/PDR/index.htm

Paraná. Secretaria Estadual de Saúde. (2005). Política Estadual de Saúde Mental. Acesso em 14 de janeiro, 2008, em http:// www.saude.pr.gov.br

Pereira, M. A. O. \& Bellizzoti, R. B. (2004, dezembro). A consideração dos encargos familiares na busca da reabilitação psicossocial. Rev. Gaúcha Enferm., 25(3), 306-313.

Pitta, A. M. F. (Org.). (1996). Reabilitação psicossocial no Brasil (Coleção Saúde Loucura, 10). São Paulo: HUCITEC. 
Rosa, L. (2003). Transtorno mental e o cuidado na família. São Paulo: Cortez.

Tonini, N. S. (2005). O planejamento em saúde mental no contexto da reforma psiquiátrica: um estudo dos municípios da região oeste do Paraná. Tese, Programa de Pós Graduação em Enfermagem Psiquiátrica, Universidade de São Paulo, Ribeirão Preto, SP.

Tonini, N. S. \& Kantorski, L. P. (2005). Planejamento estratégico e as políticas de saúde mental. Revista Gaúcha de Enfermagem, 28(1), 126-32.

Ana Silvia Scandolara, Angela Rockenbach, Emerson Aparecido Sgarbossa e Lilian Rafaela Linke são

Discentes do Curso de Psicologia da Universidade

Paranaense - UNIPAR - Campus Cascavel/Pr. Bolsistas do Programa Institucional de Bolsas de Iniciação Científica (PIBIC) no ano de 2007.
Nelsi Salete Tonini é Enfermeira, Doutora em Enfermagem Psiquiátrica pela Universidade de São Paulo

- Ribeirão Preto/SP. Docente da Universidade Paranaense - UNIPAR - Campus Cascavel/Pr. Endereço para correspondência: UNIPAR, Rua da Bandeira, 447. Centro. Cascavel/Pr. CEP: 85812-270.

Email: tonini@unipar.br

\section{Avaliação do Centro de Atenção Psicossocial Infantil de Cascavel - PR}

Ana Silvia Scandolara, Angela Rockenbach, Emerson Aparecido Sgarbossa, Lilian Rafaela Linke e Nelsi Salete Tonini

Recebido em: 08/07/2008

Revisão em: 25/11/2008

Aceite final em: 22/07/2009 